\title{
Algorithmic Art Machines
}

\section{Ernest Edmonds}

IOCT, Leicester Media School, De Montfort University, The Gateway, Leicester LE1 9BH, UK; ernest@ernestedmonds.com

Received: 1 November 2017; Accepted: 10 January 2018; Published: 15 January 2018

Abstract: The article reviews the author's personal development in relation to art made by algorithmic machines and discusses both the nature of such systems and the future implications for art.

Keywords: art; computer; algorithm; machine

\section{Introduction}

The paper presents a personal narrative about my exploration of algorithmic art machines. Together with Stroud Cornock I presented a paper at a 1970 Computer Graphics conference, Computer Graphics '70 (CG70), held at Brunel University, UK. The title of the paper was "The Creative Process where the Artist is Amplified or Superseded by the Computer". In it, we discussed the advent of the computer and the implications for art and for the role of the artist. Would this machine become the artist of the future? Would the artist of the future have any role at all? The paper was later published in Leonardo (Cornock and Edmonds 1973). Since we first wrote that paper nearly 50 years ago, time has passed and in this article I will consider what has happened in that interval, thinking particularly about how my own work has developed in this context. I will re-visit our thoughts from 1970 and speculate on what comes next. What follows will consider algorithmic machines in the context of making art. Algorithmic machines are at the centre of modern life in almost all of its aspects and art does not stand apart from this. In this context, I again pose the question that Stroud Cornock and I addressed in 1970: is the artist amplified or superseded by the computer?

\section{Background}

I first used a computer in my art practice when making my relief Nineteen, 1968-69, see Figure 1. For this work, I wrote a program that helped me solve a problem that I had with determining the layout of the 20 constituent pieces. More important, however, was the fact that this use of programming to solve a problem alerted me to the potential significance of computer programming, of algorithms, to art. I saw that algorithms could be used to generate art and also that the underlying order that such a process implies was significant for the perception of art made in this way. 


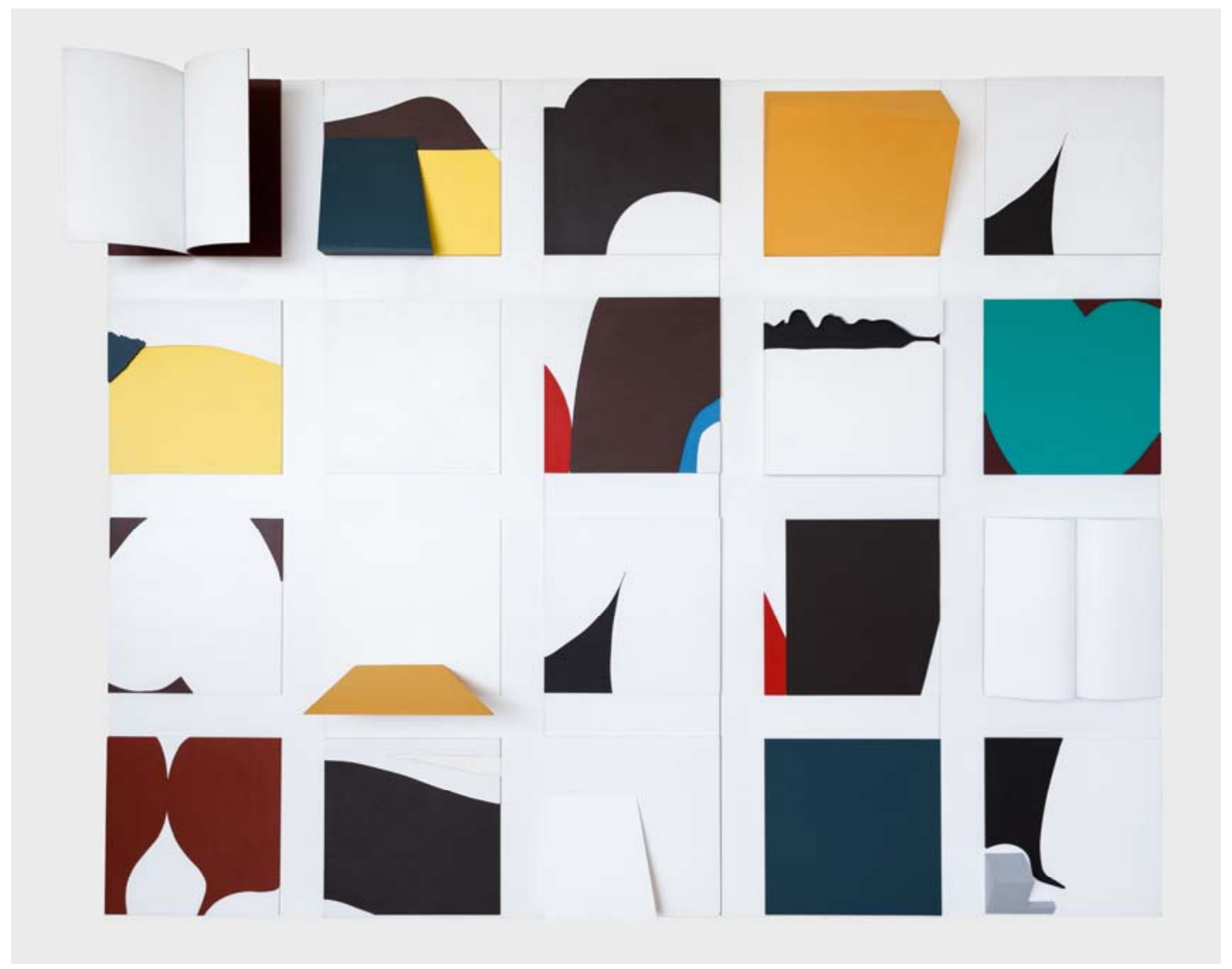

Figure 1. Ernest Edmonds, Nineteen (1968-69).

I became interested in algorithmic structures in two respects relevant to this article: first, the use of them is one way in which I make decisions about a work and reduce the specific choices. In making a work, the apparent freedom of the almost infinite range of possibilities is a difficulty. As, for example, Stravinsky claimed, true freedom comes with the application of constraints (Stravinsky 1942). After all, how is one to select from the infinite? This is, for example, the problem of facing the blank canvas or the clean sheet of paper. It is necessary to find a way of reducing the options to a manageable level. One way of doing this is to select a structure to which the work will conform, such as an algorithm for determining the form. In fact, the choice or design of such an algorithm is a major aesthetic decision in itself. The second respect in which I became interested is that constructive psychology, and the very existence of science, suggests that the search for order is a fundamental attribute of human perception: the face seen in the stain on the wall. See for example (Fosnot 2005). It is possible or even probable that structures in artworks are very significant in our aesthetic experience of them. This may be so even if we do not know or notice the specifics. We often say that a work has a satisfying form, such as in a final movement to a symphony, even when we cannot quite explain what caused our feeling of satisfaction. It is as if we respond to the architecture of a piece of music or a novel before we can unravel its construction. We may not know about the algorithm that generated a work, but we might at least sense its existence, as exploited by the UK Systems artists (Bann 1972).

I first explored the algorithm in drawings and paintings where the process of making was determined in advance-I designed an algorithm for the purpose-and where I followed the procedure by hand. For example, in the drawing shown in Figure 2, I decided in advance what lines should be drawn and in what order I should draw them. I then just acted rather like a computer in obeying those rules. There is more to the drawing and its structure, but this point will do for our purpose. Of course, I could have put those instructions into a computer program and had a plotter draw the 
image, which is fine. In this case, however, I wanted to experiment with the process of following the algorithm myself. I was interested in the act of drawing and the micro decisions that I made as I put pen to paper, as well as in the order that the algorithm gave. This approach was not possible in the next development: time-based art.

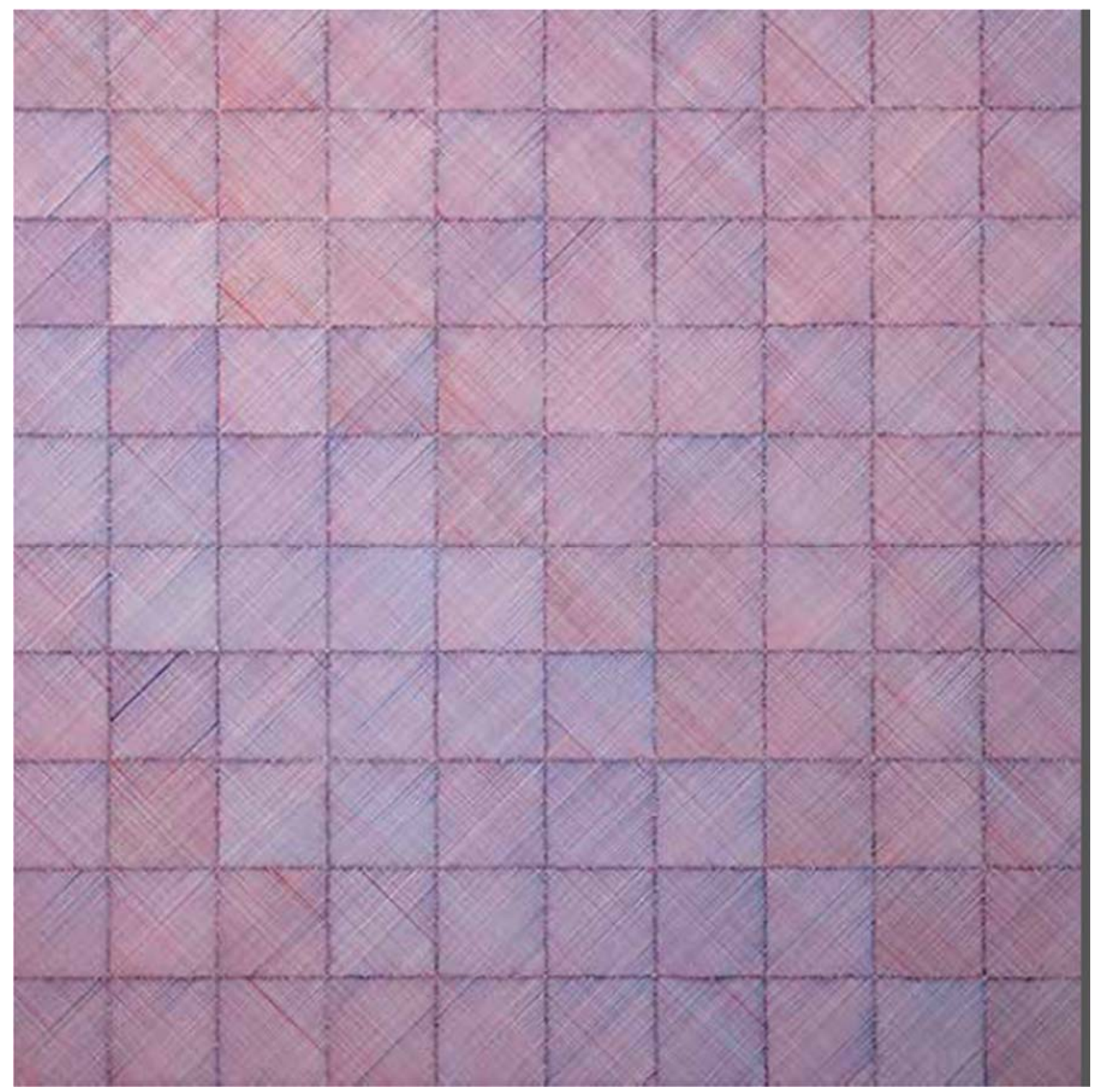

Figure 2. Ernest Edmonds, Drawing: 7 (1975).

Algorithmic art is produced with the aid of a computer by programming it to follow some procedure that generates the art object. Much of the early work of this kind produced drawings executed on a graph plotter or was drawn by a human as in the case described above. Today, however, such processes are often associated with time-based art in which the generation of images is seen as a 'projection' over time by the audience or viewer (Le Grice 1977).

Between 1980 and 1985, I developed a system for making time based abstract artworks that were generated by computer in real time (i.e., in the time employed for projection) and recorded directly onto videotape. The first completed piece was Fragment which lasted an hour and was shown as part of an art exhibition in London in 1985 (Edmonds 1985). See Figures 3 and 4. The images consisted of various arrangements of black and white squares as well as pure black and pure white frames. The key point about this work was the full incorporation of the time element into the generative process 
implemented within the computer. Time was a concrete part of the constructed work. In Fragment, and other work done at that time, both the images and the timing are determined by the generative rules as the computer system works through them. The totality of the work, with the exception of its physical manifestation, is therefore completely implicit in the defining rules. For a discussion of the construction of these works see (Edmonds 1988).

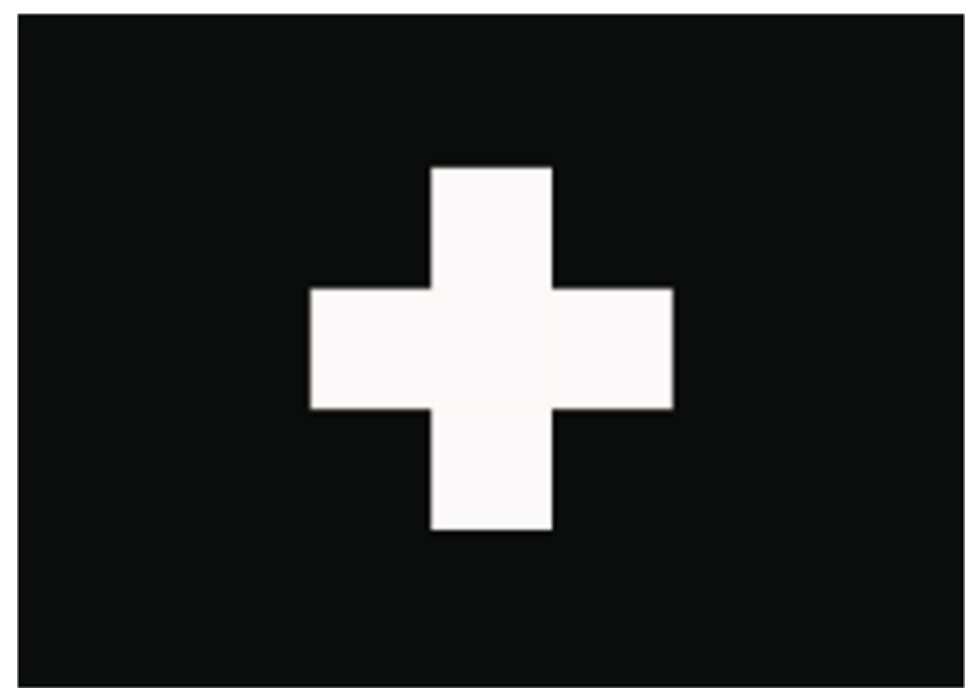

Figure 3. Ernest Edmonds, still from Fragment (1964-65).

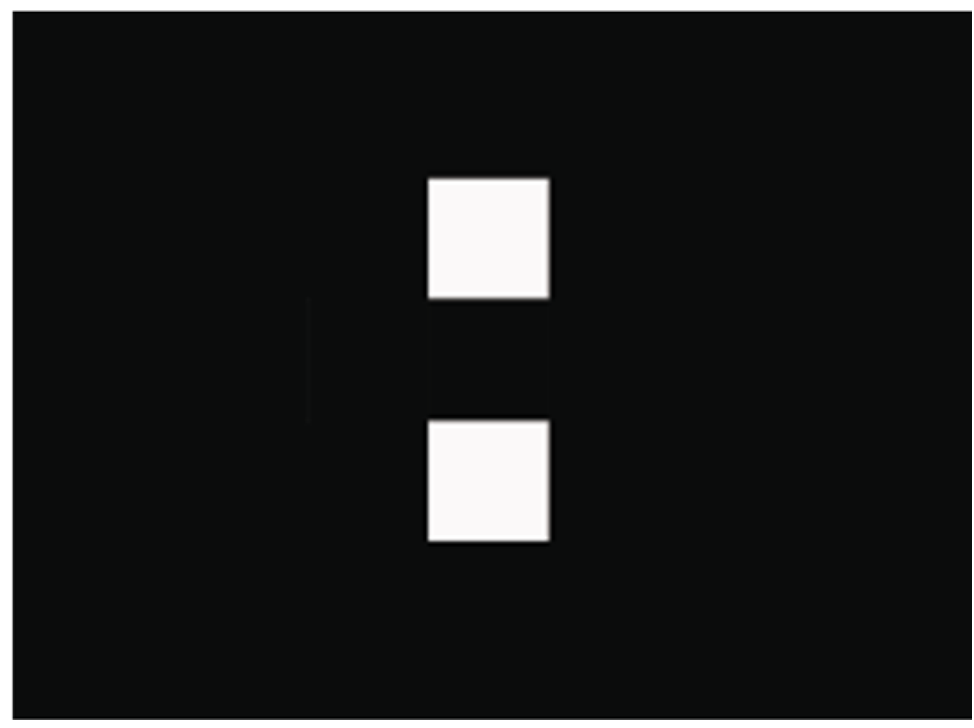

Figure 4. Ernest Edmonds, still from Fragment (1964-65).

The algorithmic system that generates a work such as Fragment is, of course, a closed system. That is to say, the system is entirely self-contained and has no exchange with any other system, that is, it has no exchange with the outside world. Many artists add calls to random number generators - technically pseudo random numbers (Strawderman 1965) —into their algorithms so that the resulting works are unpredictable and/or are different each time the algorithm is run. The motives vary, but include the idea of simulating 'creative' interventions and simulating interchange with a world outside the algorithm (Baggie 2008). I use another approach. After making the series of works starting with Fragment, I began to make works where the algorithmic system was open, where the system had exchanges with its environment taking readings from sensors, for example, and 
progressing in different ways depending on the values of those readings. In plain language, I was making interactive systems: something discussed in some detail in the 1970 paper mentioned at the beginning of this article, and which has been central to much of my recent work (Edmonds 2003).

We can think of the algorithms used for open systems as having a meta-logic that draws upon the exchanges with the outside world-for example reacting to the detection of movement. The meta-logic can automatically change the algorithms used to generate the artwork. The obvious case is where the algorithm is prompted to respond directly to a stimulus. However, that need not be the case. The meta-rules can change the algorithm so that its potential behaviour in the future is modified, without there necessarily being any immediate reaction to the stimulus. A person can learn without performing any observable action. A teacher might face still and blank looking students, but they might in fact be learning. I call this kind of interaction 'influence' (Edmonds 2007).

A book by Francesco Franco describing a fuller picture of my artistic journey has recently been published (Franco 2018).

\section{Algorithmic Machines and Art}

In the modern world the algorithm, in its various forms, is central to so much of life. From the washing machine to the car and airplane, from selecting a holiday to trading shares, from finding a book to finding a friend, algorithms control or influence the process. In the 19th century, a machine was a mechanical thing; but in the 21st century, the essence of most machines is to be found in an algorithm.

In many cases, the algorithms used in machines are relatively clear sets of procedural instructions or declarative rules: "do this, then that and on some condition do something else" or "always meet this condition and don't allow this state to arise". However, more and more we seem to be confronted with artificial intelligent (AI) machines. Exactly what an artificially intelligent machine is may not be all that clear, but one thing that is certain is that the details of how such machines work is obscure to most people. Briefly, there are two main classes of such machines, those using symbolic AI and those using connectionist AI. The algorithms that drive a symbolic AI system can be seen as explicit sets of rules, formal statements, about the subject of concern with an engine of some kind that can act on those rules, making decisions as appropriate. The algorithms that drive a connectionist AI system, on the other hand, are essentially statistically based and are developed from a learning process. Typically, large sets of examples are used to enable the system to automatically develop the ability to make correct, or appropriate decisions. For example, face recognition systems are typically of this kind. There are plusses and minuses for both kinds of AI. Connectionist AI systems have proved very successful in many recent applications. They are, however, obscure in the sense that they do not easily reveal the reasoning behind any given decision. It is somewhat easier to draw such explanations out of a symbolic AI system.

Procedural, declarative, and AI algorithms, of whatever sort, may have different implications for art. For example, a declarative algorithm could well match a set of specific composition rules that an artist wants his work to conform to. The algorithm might then embody explicit qualities that are desired. On the other hand, a connectionist algorithm might be used to recognise a face and so enable the artist to arrange that the work responds in a particular way when someone is looking at it.

\section{Amplified or Superseded?}

As mentioned above, in the 1970 paper, Stroud Cornock and I considered the issue of whether the computer, our algorithmic machine, might amplify or just supersede the artist. Without repeating the full argument, our basic thinking then was that "Though the computer can replace man in the production of graphic images, its function in the arts is seen as assisting in the specification of art systems and in their subsequent real-time management." In particular, we said that "The traditional role of an artist is clearly called into question by these developments ... so that when one speaks of an 'artist' one means he who is performing a kind of catalysis of creative behaviour within society and not a specialist working for a section of that society. His major function might, therefore, be to initiate." 
The thinking behind these remarks was driven by the whole idea of computing. We considered the issue of where the humans, the artists, might find themselves. The answer, as we then saw it, was that the artist would become the figure who, as it were, set things up. So, whilst in some sense the computer might be left to create the artwork in detail, the artist would have defined the framework within which the situation was defined. Looking back on that position, it seems hard to take a different view. So, for the moment, I confirm that early position.

Another issue, not discussed in the 1970 paper, is the role of algorithms in the art making process. It turned out that after my making of Nineteen this was crucially important in my own development. As I have described above, but now re-conceptualised, the important issue of using an algorithm as an art making process was a critical advance. This idea was widespread as we know well but the particular significance in our context is the degree that it ties the invention of computation, of the general purpose computer, to a way of making art.

The underlying structures of the artwork can now be seen in computational terms. The algorithms create the work whilst, of course, the artist creates the algorithms (GV Art 2014).

\section{Conclusions: The Significance of the Algorithmic Machines in Art}

The thoughts that are recorded in this article were brought to a particular significance with the Algorithmic Signs exhibition in Venice (Franco 2017). In this show, I exhibited along with Manfred Mohr, Vera Molnar, Roman Verotsko, and Frieder Nake. All of us used algorithms to make our art and many of us had done that for 50 years or so. What was the incisive point about the show? For me it came from a conversation with someone who was not deeply into visual art but had been deeply into computing for very many years (Catton 2017). The point that we jointly discovered was that this exhibition of algorithmic art represented art that engaged with the key issues that are part of modern life. Very many aspects of life are conducted by—or influenced by—algorithms, from selecting a holiday to obtaining a loan. In the developed world, at least, we could argue that our lives are partly driven by algorithms and yet they remain an unexplored territory for many people. So this kind of art is engaged with contemporary life like no other. The old Cornock/Edmonds issue of "amplified or superseded" has not changed - the computer, the algorithm, the machine-is still something that the artist uses to create a framework of some kind. However, the metaphor of the algorithm, as used in art, is surely a metaphor of life itself, as we know it today. So I argue that this work is in no way on the edge of contemporary art, but is at the very core of our contemporary concerns.

Conflicts of Interest: The author declares no conflict of interest.

\section{References}

Baggie, Denis L. 2008. The use of randomness in the simulation of creativity. In Natural Chance, Artificial Chance. Edited by Negrotti Massimo. Bern: Peter Lacy, pp. 25-46.

Bann, Stephen. 1972. Introduction. In Systems. London: Arts Council, pp. 5-14.

Catton, David, and Cutthorpe, Derbyshire, UK. 2017. Personal communication.

Cornock, Stroud, and Ernest Edmonds. 1973. The creative process where the artist is amplified or superseded by the computer. Leonardo 16: 11-16. [CrossRef]

Edmonds, Ernest A. 1985. Exhibition 4: Duality and Co-Existence. London: Exhibiting Space.

Edmonds, Ernest A. 1988. Logic and time-based art practice. In Leonardo, Electronic Art Supplemental Issue. Oxford: Pergamon Press, pp. 19-20.

Edmonds, Ernest A. 2003. Logics for Constructing Generative Art Systems. Digital Creativity 14: 23-38. [CrossRef]

Edmonds, Ernest A. 2007. Reflections on the Nature of Interaction. CoDesign: International Journal of Co-Creation in Design and the Arts 3: 139-43. [CrossRef]

Fosnot, Catherine Twomey. 2005. Constructivism: Theory, Perspectives, and Practice, 2nd ed. New York: Teachers College Press.

Franco, Francesca. 2017. Algorithmic Signs. Available online: http:/ /www.bevilacqualamasa.it/en/algorithmicsigns? uniq=f16445051ee333ea5f002352aca01f2e (accessed on 1 December 2017). 
Franco, Francesca. 2018. Generative Systems Art: The Work of Ernest Edmonds. London: Routledge.

GV Art. 2014. Automatic Art. London: GV Art.

Le Grice, Malcolm. 1977. Abstract Film and Beyond. London: Studio Vista.

Stravinsky, Igor. 1942. The Poetics of Music. Cambridge: Harvard University Press.

Strawderman, William E. 1965. Generation and Testing of Pseudo-Random Numbers. Ithaca: Cornell University.

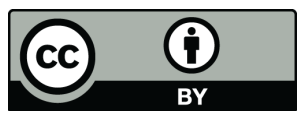

(C) 2018 by the author. Licensee MDPI, Basel, Switzerland. This article is an open access article distributed under the terms and conditions of the Creative Commons Attribution (CC BY) license (http:/ / creativecommons.org/licenses/by/4.0/). 